\section{Reply to Revusky}

\author{
DENIS MITCHELL \\ Department of Zoology, Duke University \\ Durham, North Carolina 27706
}

I purposely worded the statement in question to imply that there has been a consistent failure of researchers concerned with the delay of reinforcement effect to include appropriate controls, and I suggested that the reader compare (cf.) several typical examples. Among his objections, Revusky (1977) suggests that we used "unscholarly secondary sources" in selecting suitable examples. Though I may not have made the points raised in the Discussion section of our paper (Mitchell, Scott, \& Mitchell, 1977) as clear and as specific as I might have, it was not because I had not examined the primary sources. In fact, I selected the three papers from among the dozen or so in my files primarily because they are, in my view, the most widely cited.

Virtually all of Revusky's present objections reflect what my students and I have come to call "the taste-aversion double standard." For example, in his paper, Revusky (1968) uses X-irradiation as the UCS in doses ranging from 50 to $250 \mathrm{R}$. There is little doubt that animals exposed to X-rays of this magnitude, especially the higher dose (which is approximately one half of the $\mathrm{LD}_{50}$ ), remain "sick" for several days following treatment (as evidenced by prolonged hypophagia). Though he readily accepts his own data gleaned from "sick" animals, he questions ours. Clearly, he is using different criteria to assess those results which support a learnedassociation interpretation than those which do not. In any event, the similar performance of the animals poisoned immediately after water consumption and those given a sham injection immediately following water consumption in our experiment (Mitchell, Scott, \& Mitchell, 1977) argues against the objections raised by Revusky and Garcia (1970) concerning the testing of supposedly sick animals. If illness alone caused the avoidance, why did those animals which were not poisoned initially avoid the saccharin?

Another example of this double standard is Revusky's insistence that when animals poisoned some hours after consuming the CS do not subsequently avoid it, they constitute "noncontingent poisoned controls." But, when similarly treated animals avoid the CS, they constitute an experimental group that has formed an association over a long delay (Revusky, 1968). Clearly, he wants to avoid his saccharin and drink it too.

The real issue here is our finding of a significant avoidance of the CS (.1\% saccharin) by both noncontingently poisoned and sham-injected animals that had no prior experience with the CS (or any other novel solution) prior to the preference test. Revusky's failure to find similar effects in his first experiment (Revusky, 1968, p. 17), was probably due to a combination of factors, including the use of milk as the familiar solution (the animals were given only five 5-min exposures to milk prior to testing), the small number of animals in each control group ( $\mathrm{N}=2$ animals/treatment condition) as opposed to each experimental group ( $N=8$ animals/treatment condition), and the fact that his "irradiated controls" were given access to the sucrose solution 4 days prior to treatment. In his second experiment, " ... irradiated controls were not used" (Revusky, 1968 , p. 19). In his third and final experiment, he did not use sham-treated controls and his "irradiated controls" were tested in the same way as in his first experiment (Revusky, 1968, p. 20).

As for the two additional papers we cited, Smith and Roll (1967) did not include noncontingently poisoned controls in the single experiment they report. Garcia, Ervin, and Koelling (1966) conducted two experiments ( $A$ and $B$ ). In Experiment $A$, the noncontingently poisoned controls were not tested with the CS (saccharin) at any time during the experiment, but "drank water every day" (Garcia, Ervin, \& Koelling, 1966, p. 121). In Experiment B, noncontingently poisoned controls were not included.

I submit that the procedures reported in these three papers were not adequate to rule out the possibility that nonassociative factors play a significant role in the taste-aversion paradigm. It seems to me that noncontingently poisoned controls should have no prior experience whatever with other novel solutions or with the solution subsequently used as the novel choice during preference testing. In the main, I am not impressed with Revusky's present objections and I remain skeptical of the methods he employed in his experiments (Revusky, 1968). I remain in essential agreement with those who caution against accepting a plausible account when so little is known about the variables involved (Krane \& Wagner, 1977), and with Bitterman's conclusion that "problems of control abound in these aversion experiments, perhaps because they are not always uppermost in the minds of the investigators" (Bitterman, 1975).

\section{REFERENCES}

Bitterman. M. E. The comparative analysis of learning. Science. 1975, 188, 699-709.

Garcia, J., Ervin, F. R., \& Koelling, R. A. Learning with prolonged delay of reinforcement. Psychonomic Science, 1966, 5. $121-122$.

Krane, R. V., \& WAgner, A. R. Taste aversion learning with a delayed shock US: Implications for the "generality of the laws 
of learning." Journal of Comparative and Physiological Psychology, 1977, 88, 882-889.

Mitchell. D.. Scott. D. W., \& Mitchell, L. K. Attenuated and enhanced neophobia in the taste-aversion "delay of reinforcement" effect. Animal Learning \& Behavior, 1977. 5. 99-102.

Revusky, S. H. Aversion to sucrose produced by contingent $\mathrm{X}$-irradiation. Joumal of Comparative and Physiological Psychology, 1968, 65, 17-22.

Revusky. S. H. Correction of a paper by Mitchell, Scott, and
Mitchell. Animal Learning \& Behurior, 1977. 5. ()(1)-000.

ReVusKy, S., \& GARCIA, J. Learned associations over long delays. In G. H. Bower (Ed.). The psychology of leaming and motivation: Advances in research and theory (Vol. 4). New York: Academic Press, 1970.

Smith, J. C., \& Roll, D. L. Trace conditioning with X-rays as aversive stimulus. Psychonomic Science, 1967, 9. 11-12.

(Received for publication May 5, 1977 . accepted May 10, 1977). 